\title{
Seismic Response of Peaty Organic Soils as a Levee Foundation Material
}

Robb E. S. Moss and Justin C. Hollenback

\begin{abstract}
The dynamic response of peaty organic soils is not well understood but its poor competency as an engineering material is well known. Its use as a foundation material is generally avoided through careful selection of project location, or removal and replacement with more suitable material. In certain situations peaty organic soils are unavoidable because of prior land use and subsequent development of infrastructure. In a delta environment levees are often found to be overlying peaty organic deposits, the California Bay Delta and New Orleans levee systems are two important examples. The Bay Delta is in a seismically active area and dynamic response of peaty organics underlying these levees is a concern. This research develops a first-order estimate of the large strain dynamic response of peaty organic soils, with the goal of improving system reliability estimates of the Bay Delta levee network. Suites of cyclic triaxial tests on manufactured and sampled peaty organic soil specimens have been carried out, the results of which are used to inform finite element modeling of the levees subjected to seismic loading. We use a finite element program with existing constitutive models to provide deformation estimates of typical levee cross-sections in the Bay Delta. The deformation estimates are in turn used to improve the system reliability estimates of the Bay Delta levees. A full understanding of the dynamic response of peaty organics will require more testing and the development of more specific constitutive models; however for the goal of improving system reliability estimates this first-order approach is adequate within the bounds of all other contributing uncertainties.
\end{abstract}

\section{INTRODUCTION}

The Bay Delta is an important asset to California's infrastructure. Unfortunately it also happens to be a fragile system. The Bay Delta is the outlet for primarily the Sacramento and San Joaquin River systems. Together these rivers, and their respective tributaries, drain most of the western slope of the Sierra Nevada Mountains and the eastern slope of the Coast Ranges (Kern County to Shasta). In total the Bay Delta drains an area of 1.1 million square kilometers. The Bay Delta itself consists of a network of channels confined by a system of more than $1700 \mathrm{~km}$ of levees, sections of which are up to $7.5 \mathrm{~m}$ tall. Figure 1 shows the location of the Bay Delta and its watershed. Many of these levees were poorly constructed with 
little or no engineering considerations taken into account. Furthermore almost $60 \%$ of the Bay Delta is underlain by at least $2 \mathrm{~m}$ of peaty organic material, generally located in the western side. These levees protect a collection of 65 islands and tracts, many where water level behind the levee is permanently higher than land side elevation (below mean sea level) even during times of low water level. This network of channels is also a hub for both regional and state wide infrastructure consisting of, but not limited to: major highways, deep water shipping channels, railway lines, power transmission and distribution, and water distribution. The water distribution function of the delta is arguably the most important. The Bay Delta serves as a hub for a large portion of the state's water supply, as roughly $25 \%$ of urban water used in the state is diverted through it. Approximately $2 / 3$ of the population relies on the Bay Delta for some portion of their drinking water and nearly 3 million acres of farmland depend on the Bay Delta for some quantity of irrigation water. In a worst case scenario a major earthquake in the bay area could result in the failure of hundreds of kilometers of levees. This would, among other things, result in salt water contamination of the fresh water in the delta rendering it useless as a source of fresh water for a period of months, possibly years (URS, 2008).
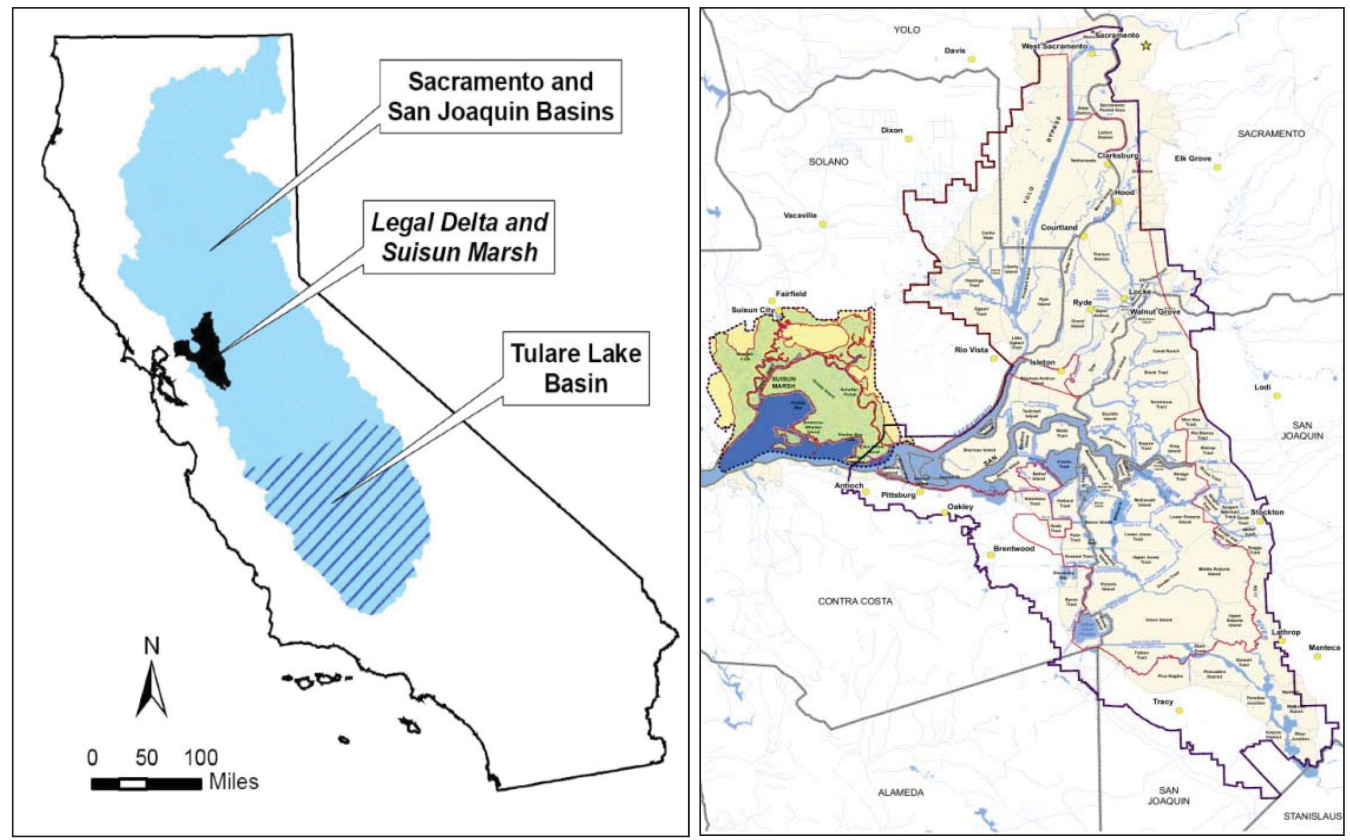

Figure 1. Left, Bay Delta water shed, right, map of Bay Delta (after Phase 1 DRMS Report, URS 2008).

Even in a strong economic environment, and a state budget surplus there would not be enough money to fix every levee in the delta that needs repair. The motivation of this research is to improve current risk estimates in the Bay Delta as to insure the limited time and resources get spent on levees that pose the most risk. Risk is the product of the probability of failure of a system and the consequences of that failure. The probability of failure is usually annualized and the consequences are in units of economic or societal significance (e.g., life loss, damage in dollars, area of 
land flooded, etc.). An improved understanding of large strain dynamic peat response, a more robust consideration of spatial variability, and improved procedure for calculating system reliability will produce more refined and accurate risk assessments. In this paper we will focus on the dynamic response of peaty organics but will also begin to develop a framework to integrate all three concepts.

A suite of cyclic triaxial tests on manufactured peaty organic soil specimens have been performed. These tests have been run at varying cyclic stress ratios and consolidation stresses. Along with cyclic triaxial tests, post-cyclic compressive strength tests were compared to compressive strength tests on pristine samples to quantify change of strength due to cyclic loading. Finally post-cyclic reconsolidation is measured to gain insight into how much free board might be lost after shaking as associated increased pore pressures are allowed to dissipate. The decision to use manufactured samples was driven by the difficulty in acquiring field samples both technically and logistically. The specifications of manufactured soils are discussed further herein. Comparisons of cyclic triaxial test results are made between our manufactured samples, similarly tested field samples, and other researcher's field samples. Results of these lab tests are used to calibrate material properties of finite element analysis, which are in turn used to estimate seismically induced levee deformations. For this analysis the program PLAXIS and its existing constitutive models are used. Historically an important step of any numerical modeling analysis is calibration of model results with a well documented field case history. Unfortunately, we are unaware of any well-documented case history of seismically loaded levees with peaty organic foundation soils. It should be emphasized here that this modeling is intended to be a first order approximation of deformation. It is recognized that to understand the finer details of seismically induced levee deformation of levees with peaty organic foundation material a more robust analysis must be performed. This paper is intended be a starting point for more detailed analyses.

\section{SPATIAL VARIABILITY AND SYSTEM PROBABILITY OF FAILURE}

Spatial variability of measured properties (undrained strength, percent organics, plasticity index, median grain size, etc.) is inherent to geotechnical materials. Quantifying spatial variability of properties of interest can be crucial to the accuracy of a reliability (the additive inverse of probability of failure) estimate for large geotechnical systems such as levees (Moss et al., 2010). Levees operate as series systems; if one section of a levee (i.e., one component of the system) fails the entire system has failed. The reliability of a series system is directly proportional to the number of components in that system. The more components in a system the more opportunities the system has to fail and the higher the probability of failure for the given system.

In general, levee systems have been divided into components or reaches (individual levee sections) inconsistently, either through subjective examination of soil properties and levee geometries (URS, 2008) or with an arbitrary, predetermined, reach length that is not specific to a project or depositional environment (van Manen and Brinkhuis, 2005). Levee reach length, and thus number of reaches, can be 
objectively determined using a spatial statistics tool called an experimental semivariogram (Figure 2) to quantify the spatial variability of a property of interest for a specific mode of failure (Moss et al., 2010).

An experimental semi-variogram quantifies dissimilarity of data as a function of separation distance. As a brief example, consider a CPT sounding in a deposit of alluvial sand. Measurements of tip resistance separated by $0.2 \mathrm{~m}$ (e.g., readings at depths of $2.2 \mathrm{~m}$ and $2.4 \mathrm{~m}$ or $5.3 \mathrm{~m}$ and $5.5 \mathrm{~m}$ ) are more likely to be similar than measurements separated by $3.0 \mathrm{~m}$ (e.g., readings at depths of $3.4 \mathrm{~m}$ and $6.5 \mathrm{~m}$ or 1.3 $\mathrm{m}$ and $4.5 \mathrm{~m}$ ). Experimental semi-variograms are produced by calculating the semivariance of all samples that are separated by a given distance and repeating this for several different distances. Experimental semi-variance for a given distance is one half the average squared difference and can be calculated for any property of interest (e.g., undrained strength, permeability, tip resistance).

Figure 2 shows a conceptual semi-variogram that represents the expected trends with a continuous function. An experimental semi-variogram derived from field data however is only defined for a discrete number of separation distances (Isaaks and Srivastava, 1989). Examining Figure 2 we see that for small separation distances the semi-variance is small and as separation distance increases semivariance increases until it asymptotically approaches some maximum value, referred to as the plateau. The separation distance beyond which the semi-variance behaves asymptotically is defined as the range. Experimental semi-variograms constructed from field data have some degree of scatter depending on amount and quality of data but generally follow the trends described above and seen in Figure 2.

The range from an experimental semi-variogram is used to define the length of a levee section or reach for a given failure mode. The range is essentially the separation distance at which samples reach their maximum statistical independence (i.e., minimum correlation). Consider a levee system and a failure mode due to poor performance of a peat layer and its insufficient strength. The range of an experimental semi-variogram, made from shear strength data of peat collected throughout the levee system, provides a reach length for the levee system for a specific failure mode that is defined by the spatial continuity of a parameter controlling the failure mode. This can be repeated for any failure mechanism of concern and controlling parameter. Now that a reach length is defined a levee systems can be divided into components or reaches, the probability of failure for each reach (component probability of failure) can be calculated, as well as the subsequent probability of failure for the entire system. 


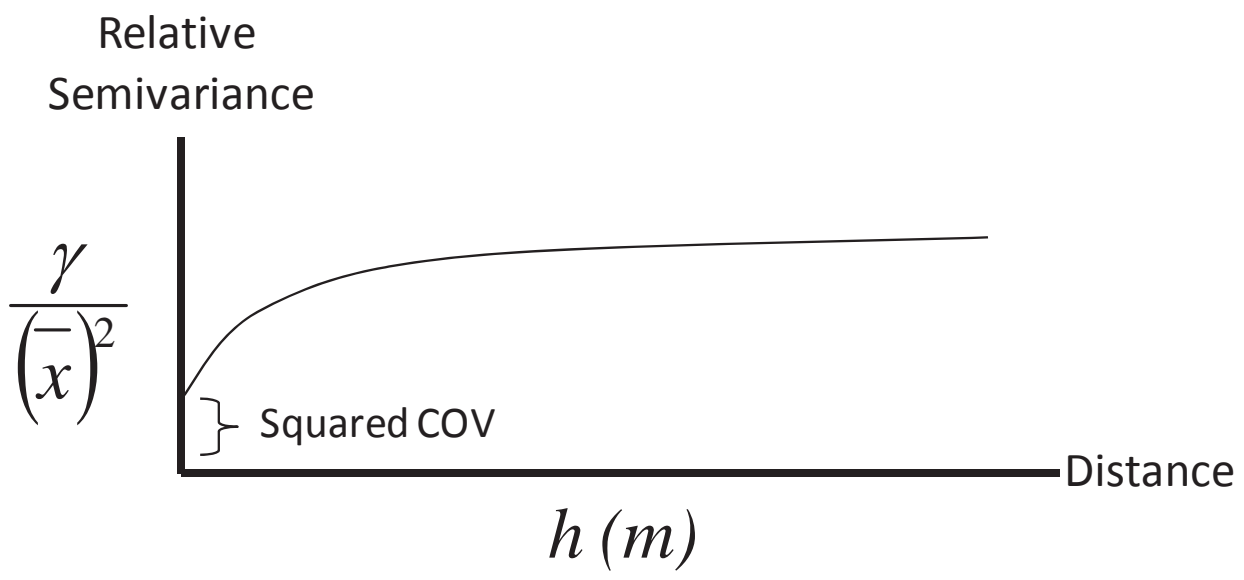

Figure 2. Conceptual diagram of variogram. A spatial statistics tool used here to define reach length of levee. Distance is plotted on the $x$-axis and relative semivariance is on the $y$-axis. Distance at which the curve flattens out represents the distance for maximum statistical independence between reaches.

In order to accurately estimate the probability of failure for individual levee reaches the response of materials to a given type of loading must be known. Currently the response of levees with peaty organic foundation materials to strong ground shaking is poorly understood. Levees that have this type of foundation material and are subject to strong ground shaking exist throughout the Bay Delta. This pairing occurs mostly in the western portion of Bay Delta, which is situated closer to seismic sources and where the peat deposits are thicker and cover more area. The following sections will layout procedures and estimates of deformations of these types of levees to seismic load.

\section{MANUFACTURED SAMPLES AND LAB TEST RESULTS}

Due, in the most part, to non-technical issues field samples have been difficult to acquire for this research. Therefore to speed the testing process, manufactured peaty organic soil samples were used for a large portion of the laboratory testing. These samples were manufactured based on target values of plasticity index, ash content, water content, undrained shear strength, and unit weight. The samples were also constructed to mimic layering patterns of peaty organic deposits observed in the field. The targeted index tests and layering scheme were chosen based on Wehling et al. (2003), Boulanger et al. (1998), and personal communications with Tim Wehling.

The peaty organic samples were constructed from four main raw materials: manure, potting soil, silt/clay, and peat. The potting soil, manure, and silt/clay were mixed together to form one layer while the peat was used as the other layer in the scheme. The peat is generic garden peat moss obtainable from any garden supply store. The soil-manure mix was placed in $2-3 \mathrm{~cm}$ thick sections alternating with thin layers of peat. This pattern was followed for the entire sample height. The PI for the soil manure mixture was targeted to be approximately 40 . Ash content of the bulk sample (soil manure mix combine with peat layers) was assigned a range of $60-70 \%$. Water content of the bulk sample was given a range of $150-250 \%$. The wide range 
on the water content reflects realistic ranges of in situ water contents for peaty organic materials. Total unit weight of manufactured samples was targeted at 12-13 $\mathrm{kN} / \mathrm{m}^{3}$. Samples were built in $30 \mathrm{~cm}$ diameter buckets and consolidated ( $\mathrm{K}_{\mathrm{o}}$ loading) to vertical stresses of $25 \mathrm{kPa}$ to $125 \mathrm{kPa}$. These stress conditions are consistent with field stress conditions beneath the toe and crest of Bay Delta levees. Samples were allowed to consolidate until primary consolidation was complete. After consolidation specimens were sampled using thin walled Shelby tube sampler with an outside diameter of $7.6 \mathrm{~cm}$.

A series of cyclic ICU (isotropically consolidated undrained) triaxial tests, with pore pressure measurements, were run at cyclic stress ratios from 0.25 to 0.50 . These tests were stress-controlled and run for 30 cycles at $1 \mathrm{~Hz}$ frequency to roughly mimic real time dynamic stress conditions. Specimens were initially isotropically reconsolidated to the vertical stress that was applied during manufacturing. Peaty organic materials in situ have been found to be partially saturated, even below the water table, due to ongoing organic decomposition (Wehling et al., 2003); therefore samples were left in their partially saturated state to mimic observed field characteristics. Results of Young's modulus $\left(E_{a}\right)$ versus cyclic axial strain $\left(\varepsilon_{c}\right)$ are compared with results from Wehling et al. (2003) and Boulanger et al. (1998) in Figure 3. This provides verification that manufactured peaty organic material is capturing the cyclic response of the sampled material that the targeted index properties are based on.

As the goal of our research is to estimate the large strain response of peaty organics, we did not test for the small strain stiffness. Therefore our data is not compared with a stiffness degradation ratio, but simply $\mathrm{E}_{\mathrm{a}}$ versus $\varepsilon_{\mathrm{c}}$. The choice of comparing stiffness data in terms of $\mathrm{E}_{\mathrm{a}}$ rather than $\mathrm{G}$ hinged on the lack of knowledge about Poisson's ratio. Axial strains and shear strains are related to each other through Poisson's ratio, thus Young's Modulus and shear modulus are also related through Poisson's ratio. It is assumed that Poisson's ratio is 0.5 for fully saturated Clay subjected to undrained loading. As a result partial saturation (B values in the range of 0.8 to 0.9 ) we are unable to assume a Poisson's ratio with any certainty. Rather than adding any additional uncertainty into our comparisons, we converted other researcher's data back into Young's Modulus data using their respective assumptions of Poisson's ratio.

Modulus reduction curves seem to agree reasonably with results of both Boulanger et al. (1998) and Wehling et al. (2003). Results plotted for tests run at 25 kPa consolidation stress between Wehling's "Free Field" and "Mid Toe" lines, which were at $13 \mathrm{kPa}$ and $43 \mathrm{kPa}$ confining stresses respectively. Results plotted for tests run at $125 \mathrm{kPa}$ consolidation stress plot just below Boulanger's data, which was tested at $200 \mathrm{kPa}$ consolidation stress. These results suggest that manufactured peaty organic soils capture the stiffness degradation behavior of peat sampled from the field.

After cyclic tests were completed pore pressures were allowed to dissipate and samples were allowed to reconsolidate. Volumetric changes were monitored and compared to original pre-shaking sample volume. This was done to determine if, 
during shaking, consolidation properties of the peaty organic materials change enough to cause the crest height of a levee to settle significantly. Preliminary results indicate post-cyclic volumetric reconsolidation strains on the order of $1 \%$.

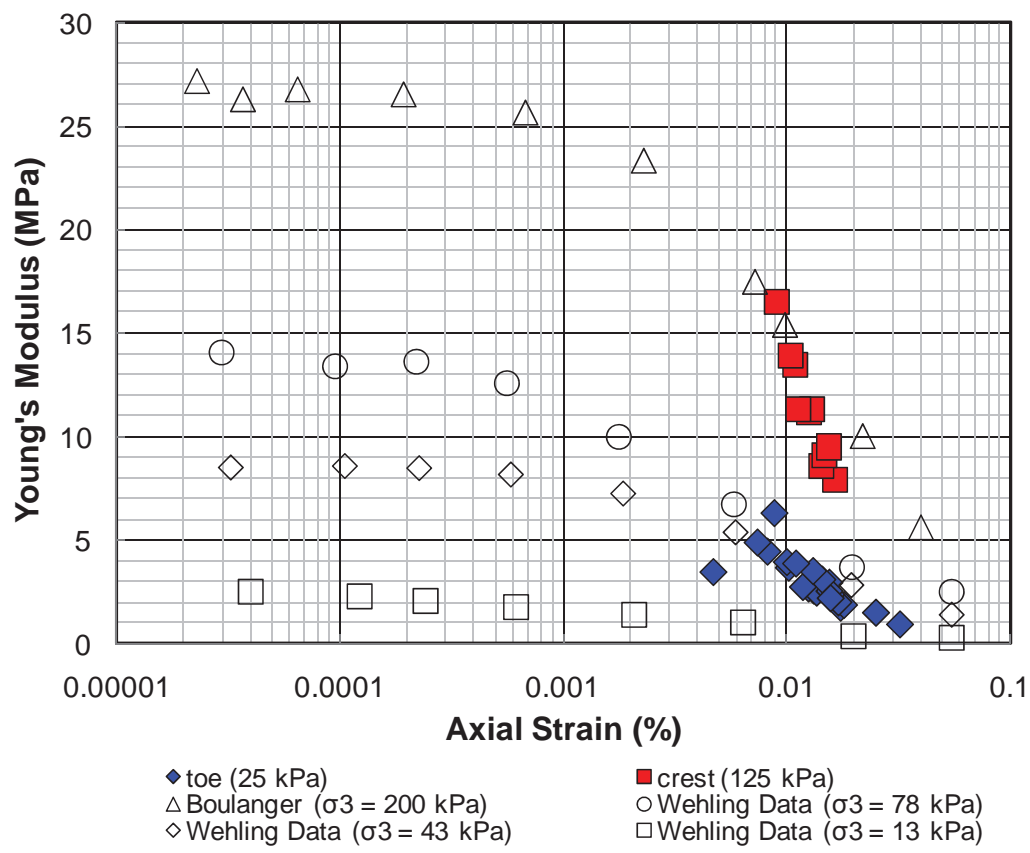

Figure 3. Comparison of Young's modulus data from Boulanger et al. (1998), Wehling et al. (2003), and this study.

In addition to cyclic ICU tests and monitoring of post-cyclic volumetric reconsolidation, post-cyclic compressive strengths were compared to the compressive strengths of pristine manufactured samples not subjected to cyclic loading. This suite of tests was performed to quantify any amount of static strength change due to cyclic loading. Initially it was thought that any tensile strength from fibrous material in peaty organics would be damaged during shaking and the strength of the bulk sample would be measurably reduced through cyclic loading. However, contrary to our assumptions post-cyclic strength consistently showed an increase when compared to pre-cyclic strength (Figure 4). The ratio of post-cyclic to pre-cyclic undrained compressive strength increase appears to be only marginally affected by confining stress, however there exists too little data at this time to draw any substantial conclusions on the dependence of the ratio of strength increase. The average ratio of strength increase for all the data was 1.5 (1.4 for $25 \mathrm{kPa}$ confining stress and 1.7 for $125 \mathrm{kPa}$ confining stress). 

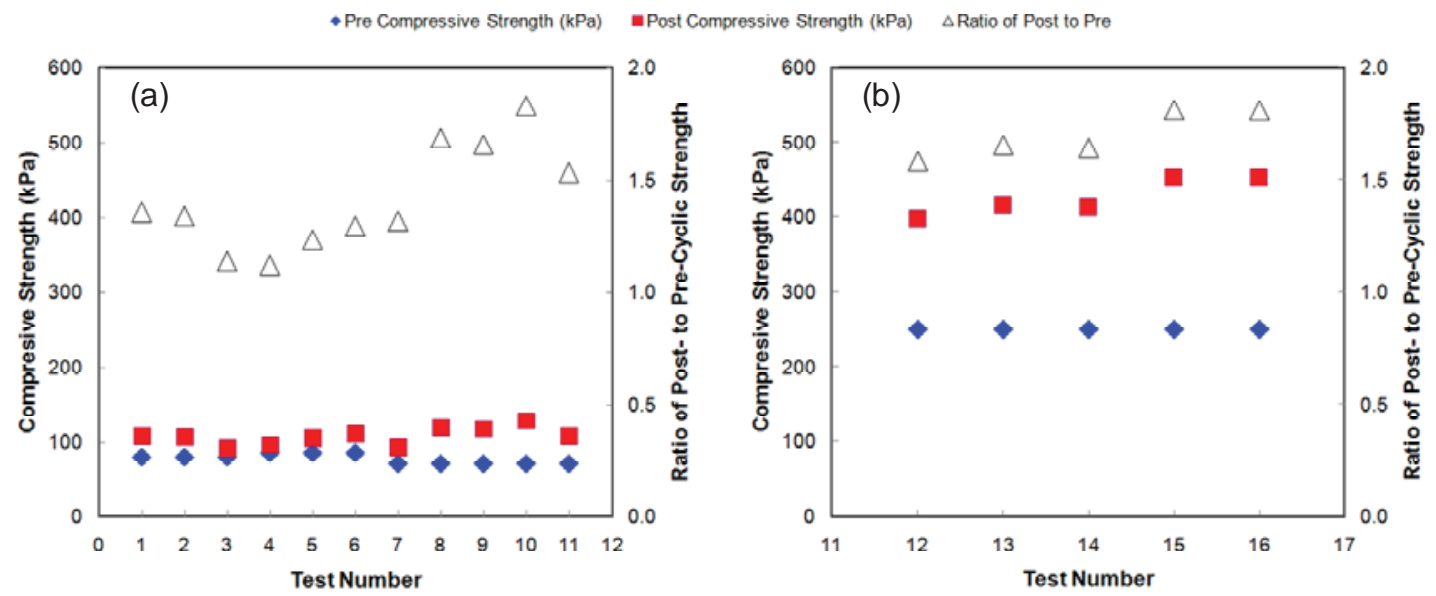

Figure 4. Pre- and post-cyclic compressive strength data for samples with (a) $25 \mathrm{kPa}$ confining stress, and (b) $125 \mathrm{kPa}$ confining stress.

\section{MODELING}

The goal of the numerical modeling in this study is to develop a procedure to estimate seismically induced deformation of levees that have peaty organics as foundation material. As a result of our findings from lab testing, modeling is focused on deformations caused by post-cyclic volumetric reconsolidation. A peat layer underlying a levee will develop moderate excess pore pressures during shaking. These excess pore pressures upon dissipation will initiate consolidation after shaking. The peat and overlying levee material will reconsolidate to a different geometry relative to its original pre-shaking geometry.

While it is acknowledge that some amount of co-seismic deformation may occur, there already exists methods for calculating co-seismic deformations of embankments (e.g., Bray and Travasarou, 2007). We are interested in developing a simplified procedure for estimating deformations resulting from post-cyclic volumetric reconsolidation based on finite element modeling. The framework of our modeling is to build a model with accurate pre-shaking stresses, strength, and consolidation properties. Then pore pressure generation will be monitored and calibrated to $r_{u}$ (excess pore pressure ratio) data generated during our cyclic tests. Lab tests show $r_{u}$ peaking at around 0.40 to 0.45 . This development of excess pore pressure and the subsequent dissipation will initiate reconsolidation. This type of deformation is thought to be the primary mechanism for crest height loss of levees founded on peaty organic soil. Figure 5 shows our qualitative sketch of the modeling and anticipated deformations. 


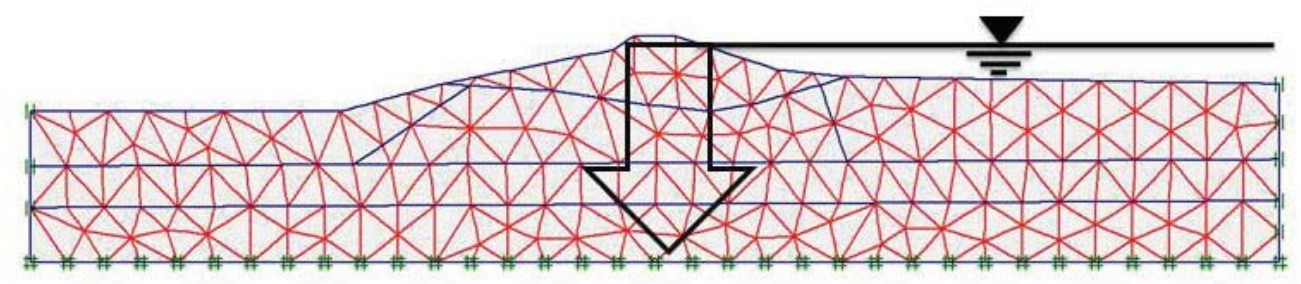

Figure 5. Finite element mesh with arrow showing qualitative deformations resulting from post-cyclic volumetric reconsolidation.

An objective is to get a rough estimate of dynamic response and incorporate it into a risk study of a large levee system. In this context the finer details are not of primary importance, only a general estimate of behavior and deformation magnitude. Therefore, PLAIXS, along with its prepackaged constitutive models is taken to be sufficient when applications of modeling results are understood. The constitutive model selected for modeling peaty organics will be calibrated using the lab test results presented here and with input from Wehling et al. (2003) and Boulanger et al. (1998). Constitutive models selected for other levee and foundation soils will be carefully selected based on general observations, past experience, and parametric studies to determine sensitivity of overall deformation estimates to response materials other than peaty organics.

Due to the wide variety of levee geometries and conditions within the delta modeling will investigate a wide variety of variables for a range of realizations. There are four main variables of interest, which are: thickness of peaty organics, depth to peaty organics, height of levee, and side slopes of levees. Conceptually we expect to see more deformations near surface thick deposits of peaty organics that are overlain by the tall levees. Complete deformation results along with a full suite of lab test results are anticipated at the time of the conference.

\section{CONCLUSIONS}

Results from this research and this type of approach are essential for the accuracy, relevance, and applicability of risk studies of large complex systems. Here the focus is on the large strain response of peaty organic soils. More detailed studies are necessary for site-specific investigations where more refined results are relevant. However, understanding response of levees with peaty organic foundation material to ground shaking on a macroscopic scale is preferred when studying large levee systems. An estimate of pseudo-static deformations coupled with an estimate of coseismic deformations, based on a preexisting method would sufficiently satisfy this macroscopic scale. This allows for a more realistic comparison with other sources of hazard, such as liquefaction. In large levee systems where conditions, geometries, and materials can vary greatly it is more beneficial to compare sources of hazard in a macroscopic way than to get overwhelmed with more detailed complex analyses. We 
hope that this paper will spark discussion and further research that will lead to further progress on the reliability of levee systems and the dynamic behavior of peaty organic soils.

\section{AKNOWLEDGEMENTS}

This material is based on work supported by the U.S. Department of Homeland Security under Grant Award Number 2008-ST-061ND0001. Administration of this grant is conducted through the Department of Homeland Security Center of Excellence for Natural Disasters, Coastal Infrastructure and Emergency Management (DIEM). The views and conclusions contained in this document are those of the authors and should not be interpreted as necessarily representing the official policies, either expressed or implied, of the U.S. Department of Homeland Security.

\section{REFERENCES}

Boulanger, R.W., Arulnathan, R., Harder, L.F., Torres, R.A., Driller, M.W. (1998). "Dynamic Properties of Sherman Island Peat." J. Geotechnical and Geoenvironmental Engineering. 124 (1): 12-20.

Bray, J.D. and Travasarou, T. (2008). "Simplified Procedure for Estimating Earthquake-Induced Deviatoric Slope Displacements." J. Geotechnical and Geoenvironmental Engineering. 133 (4): 381-392.

Clark I. (2001). Practical Geostatistics. Geostokos Limited.

Issaks, E. H., and Srivastava, R. M. (1989). An Introduction to Applied Geostatistics. Oxford University Press.

Kishida, T., Wehling, T.M., Boulanger, R.W., Driller, M.W., Stokoe II, K.H. (2009). "Dynamic Properties of Highly Organic Soils from Montezuma Slough and Clifton Court." J. Geotechnical and Geoenvironmental Engineering. 135 (4): 525-532.

Moss, R.E.S., Hollenback, J.C., Ng, J. (2010). "Spatial Variability of Levees as Measured Using the CPT." Proc. $2^{\text {nd }}$ International Symposium on Cone Penetration Testing. Huntington Beach, CA. May.

URS. (2008). Delta Risk Management Strategy (DRMS) Phase 1, Risk Analysis Report. Prepared by URS Corporation/Jack R. Benjamin and Associates, Inc., for California Department of Water Resources, December

vanManen, S. E., and Brinkhuis, M. (2005). "Quantitative flood risk assessment for Polders." Reliability Engineering \& System Safety. 90: 229-237.

Wehling, T.M., Boulanger, R.W., Arulnathan, R., Harder, L.F., and Driller, M.W. (2003). "Nonlinear Dynamic Properties of a Fibrous Organic Soil." J. Geotechnical and Geoenvironmental Engineering. 129 (10): 929-939. 